\title{
CARACTERIZAÇÃO E CLASSIFICAÇÃO DE SOLOS EM UMA TOPOSSEQUÊNCIA SOBRE CALCÁRIO NA SERRA DA BODOQUENA, MS ${ }^{(1)}$
}

\author{
Marcos Gervasio Pereira ${ }^{(2)}$, Jolimar Antonio Schiavo ${ }^{(3)}$, Ademir Fontana ${ }^{(4)}$, Antonino Hypólito \\ Dias Neto $^{(5)}$ \& Luiz Paulo Montenegro de Miranda ${ }^{(6)}$
}

\begin{abstract}
RESUMO
A serra da Bodoquena, localizada no Estado do Mato Grosso do Sul, apresenta particularidades nos seus solos, que diferem de outras regiões do bioma cerradopantanal. Este trabalho teve como objetivo ampliar o conhecimento dos solos formados sobre calcário, por meio da caracterização dos seus atributos físicos, químicos, mineralógicos e da matéria orgânica. Foi selecionada uma topossequência sobre calcário, onde foram abertas trincheiras no topo (P1), terço inferior (P2), sopé (P3) e baixada (P4 e P5). Os perfis foram descritos morfologicamente e analisados os atributos físicos, químicos e mineralógicos dos horizontes. De acordo com o Sistema Brasileiro de Classificação de Solos, os solos estudados foram classificados como: (P1) Organossolo Fólico Sáprico lítico - OOs; (P2) Chernossolo Háplico Órtico típico - MXo; (P3) Chernossolo Argilúvico Órtico típico - MTo; (P4) Gleissolo Melânico Carbonático chernossólico - GMk1; e (P5) Gleissolo Melânico Carbonático organossólico - GMk2. Todos os perfis estudados apresentaram cores escuras nos horizontes superficiais e mais avermelhadas ou acinzentadas em profundidade, em razão da drenagem, sempre associados com elevados valores de saturação por bases e tendo o cálcio como cátion predominante no complexo sortivo. Das frações húmicas, a humina representou a maior fração do carbono orgânico em todos os solos. A análise mineralógica constatou a presença de calcita na fração areia nos perfis GMk1 e GMk2 e caulinita, illita e montmorilonita,
\end{abstract}

(1) Recebido para publicação em 31 de outubro de 2011 e aprovado em 09 de novembro de 2012.

(2) Professor Associado IV, Departamento de Solos, Universidade Federal Rural do Rio de Janeiro. BR 465 km 7. CEP 23890-000 Seropédica (RJ). Bolsista do CNPq e da FAPERJ. E-mail: gervasio@ufrrj.br

(3) Professor, Universidade Estadual do Mato Grosso do Sul - UEMS, Rodovia Aquidauana km 12 UEMS/CERA, Zona Rural, Caixa Postal 25. CEP 79200-000 Aquidauana (MS). E-mail: schiavo@uems.br

(4) Pesquisador, Embrapa Solos. Rua Jardim Botânico, 1024. CEP 22460-000 Rio de Janeiro (RJ). E-mail: ademir.fontana@embrapa.br

(5) Mestre pelo Programa de Pós-Graduação em Agronomia, UEMS. E-mail: tonybioagro@hotmail.com

(6) Mestre em Agronomia, Universidade Estadual Paulista "Júlio de Mesquita Filho". Av. Brasil,56, Centro. CEP 15385-000 Ilha Solteira (SP). E-mail: luizpauloagro@yahoo.com.br 
na fração argila de todos os solos. A ocorrência do Organossolo Fólico em ambiente não altimontano, diferente do relatado pelo Sistema Brasileiro de Classificação de Solos, sugere maior amplitude das condições ambientais para a ocorrência dessa subordem.

Termos de indexação: material de origem, pedogênese, SiBCS.

\title{
SUMMARY: CHARACTERIZATION AND CLASSIFICATION OF SOILS IN A TOPOSEQUENCE ON LIMESTONE IN THE SERRA DA BODOQUENA, MATO GROSSO DO SUL, BRAZIL
}

\begin{abstract}
The soils in the Serra da Bodoquena, a mountain chain in the state of Mato Grosso do Sul, Brazil, have peculiar features that differ from other regions of the Cerrado-Pantanal biome. This study aims to characterize soils formed on limestone, based on the physical, chemical and mineralogical properties and organic matter. A toposequence on limestone was selected and profile pits were opened on the summit (P1), backslope (P2), footslope (P3) and toeslope (P4 and P5). The profiles were morphologically described and physical, chemical and mineralogical analyses were carried out in all horizons. According to the Brazilian System of Soil Classification (SiBCS), the studied soils were classified as: (P1) Organossolo Fólico Sáprico lítico - OOs (Litic Ustifolist); (P2) Chernossolo Háplico Órtico típico - MXo (Typic Haplustoll); (P3) Chernossolo Argilúvico Órtico típico - MTo (Typic Haplustoll); (P4) Gleissolo Melânico Carbonático chernossólico - GMk1 (Typic Epiaquoll); and (P5) Gleissolo Melânico Carbonático organossólico - GMk2 (Terric Haplosaprist). The color of all studied profiles was dark in the surface horizons, and reddish or grayish in deeper layers, according to the drainage conditions. Base saturation was high in all layers, with calcium as dominant cation in the exchangeable complex. Humin was the dominant organic carbon fraction of the studied soils. A mineralogical analysis showed the presence of calcite in the sand fraction in the soil profiles GMK1 and GMk2 and kaolinite, illite and montmorillonite in the clay fraction of all soils. The occurrence of Ustifolist in non-mountainous environments, different from the characterization by the $\mathrm{SiBCS}$, suggests a greater range of possible environmental conditions for the occurrence of this suborder.
\end{abstract}

Index terms: parent material, pedogenesis, SiBCS (Brazilian System of Soil Classification).

\section{INTRODUÇÃO}

Os solos desenvolvidos sob calcários cobrem uma significativa parcela das áreas agrícolas existentes no planeta (Chen \& Barak, 1982), especialmente nas regiões semiáridas. Tais solos vêm sendo utilizados e ocupados desde a idade Pré-Paleolítica, em razão da sua elevada fertilidade natural e riqueza em mananciais hídricos. Atualmente, nas áreas de ocorrência desses solos, que somam aproximadamente entre 7 e $10 \%$ do território mundial, estão assentados $25 \%$ da população global, em especial os agricultores (Shinzato, 1998).

O Brasil possui uma extensa cobertura de rochas carbonáticas e, segundo estimativas de Karmann (1994), a área coberta está entre 425.000 e 600.000 km². A sistematização dessas coberturas cársticas teve grande avanço com os estudos de espeleologia, por causa das suas peculiaridades biológicas, paleoambientais, paleontológicas, arqueológicas, além do apelo turístico (Carvalho Júnior et al., 2008), havendo, no entanto, carência de pesquisas sob a ótica de outras ciências, entre essas a pedologia (Shinzato, 1998).
No Brasil existe grande número de classes de solos que ocorrem sobre embasamento calcário, mas somente algumas são realmente influenciadas por esse material de origem. Em levantamentos de solos realizados no País, foram identificadas muitas classes de solos sobre embasamento calcário, sendo as de maior ocorrência: Chernossolos, Vertissolos, Cambissolos vérticos e, ou, carbonáticos e alguns Argissolos (Shinzato, 1998).

Sobre o embasamento calcário da região CentroOeste, a maior expressão desses solos ocorre na serra da Bodoquena, onde são verificadas variações do relevo desde forte ondulado no interior do planalto a plano ou suave ondulado nas orlas leste e oeste, dependendo da natureza das camadas que o constituem. Nessa paisagem, são observadas feições de relevo cárstico, como hidrografia subterrânea e dolinas, embora estas não sejam típicas (Embrapa, 1971).

De maneira geral, os solos desenvolvidos sob a influência do calcário apresentam em comum características, como pequena profundidade do solum; raras vezes, apresentando-se muito profundos; saturação por bases superior a $50 \%$; argilas de 
atividade alta; e valores elevados de ki, geralmente superiores a 2,5 (Shinzato, 1998).

A partir do exposto, verifica-se que a serra da Bodoquena apresenta particularidades em relação aos seus solos, que diferem de outras regiões do bioma cerrado-pantanal. Dessa forma, este trabalho teve como objetivo ampliar o conhecimento dos solos formados sobre calcário, por meio da caracterização dos seus atributos físicos, químicos, mineralógicos e da matéria orgânica.

\section{MATERIAL E MÉTODOS}

\section{Meio físico}

A área de estudo localiza-se na serra da Bodoquena, Estado do Mato Grosso do Sul (Figura 1). Foi selecionada uma topossequência sobre materiais de natureza calcária (rochas e sedimentos) e abertas trincheiras nas posições de topo (P1), terço inferior (P2), sopé (P3) e baixada (P4 e P5). Os perfis foram descritos segundo Santos et al. (2005), sendo coletadas amostras deformadas e indeformadas, com auxílio do anel de Kopeck. Informações gerais de cada perfil são apresentadas no quadro 1.

O clima da região é tropical, com temperatura média variando de 25 a $30^{\circ} \mathrm{C}$ no verão e de 15 a $20^{\circ} \mathrm{C}$ no inverno. A média pluviométrica varia de 1.200 a $1.500 \mathrm{~mm}$ anuais e o período seco dura de três a quatro meses, coincidindo com os meses de maio a agosto. A vegetação é constituída pela transição floresta estacional semidecidual/cerrado (Almeida, 1965).

A geologia da área compreende de rochas referidas ao Cambriano-Ordoviciano (Almeida, 1965); o grupo Corumbá recobre quase totalidade do planalto da Bodoquena. Constituem esse grupo, na área estudada, as formações Tamengo, Bocaina e Cerradinho, que são compostas por calcários e dolomitos, entre outros materiais.

O material de origem dos perfis estudados é constituído por rochas de natureza calcária nos perfis P1, P2 e P3, com P2 e P3 influenciados por sedimentos coluviais do calcário das partes mais altas. P1 apresenta ainda material de constituição orgânica em drenagem livre e P4 e P5 possuem como material de origem sedimentos coluviais de natureza calcária, associados a camadas de constituição orgânica formadas sob condições de drenagem impedida.

\section{Análises laboratoriais}

Realizaram-se as análises químicas e físicas na terra fina seca ao ar (TFSA). A análise granulométrica foi feita pelo método da pipeta, usando $\mathrm{NaOH} 0,1 \mathrm{~mol}$ $\mathrm{L}^{-1}$, e a densidade do solo (Ds), pelo método do anel de Kopeck. Os cátions $\mathrm{Ca}^{2+}, \mathrm{Mg}^{2+} \mathrm{e} \mathrm{Al}^{3+}$ foram extraídos com solução de $\mathrm{KCl} 1 \mathrm{~mol} \mathrm{~L}^{-1}$. A extração de $\mathrm{H}+\mathrm{Al}$ foi efetuada com solução de acetato de cálcio $0,5 \mathrm{~mol} \mathrm{~L}^{-1}$, a pH 7,0. Os teores de $\mathrm{P}, \mathrm{Na}^{+}$e $\mathrm{K}^{+}$foram extraídos com solução de $\mathrm{H}_{2} \mathrm{SO}_{4} 0,0125 \mathrm{~mol} \mathrm{~L}^{-1}+\mathrm{HCl} 0,05 \mathrm{~mol}$ $\mathrm{L}^{-1}$. Os teores de $\mathrm{Ca}^{2+} \mathrm{e} \mathrm{Mg}^{2+}$ foram determinados por titulometria com solução de EDTA $0,0125 \mathrm{~mol} \mathrm{~L}^{-1}$; $\mathrm{Na}$ e K, por fotometria de chama; $\mathrm{P}$, por colorimetria; $\mathrm{e} \mathrm{Al}^{3+} \mathrm{e} \mathrm{H}+\mathrm{Al}$, por titulometria com $\mathrm{NaOH} 0,025 \mathrm{~mol}$ $\mathrm{L}^{-1}$. Determinou-se o $\mathrm{pH}$ em água (peso $1: 2,5$ ) por meio de potenciômetro e quantificaram-se os teores de $\mathrm{CaCO}_{3}$, por ataque com $\mathrm{HCl} \mathrm{0,5} \mathrm{mol} \mathrm{L}^{-1}$, e de $\mathrm{SiO}_{2}$, $\mathrm{Al}_{2} \mathrm{O}_{3}, \mathrm{Fe}_{2} \mathrm{O}_{3}$ e $\mathrm{TiO}_{2}$, pelo ataque sulfúrico. Todos os procedimentos acima foram feitos de acordo com Embrapa (1997).

Para o horizonte superficial dos perfis $\mathrm{P} 1$ e $\mathrm{P} 5$, em razão dos elevados teores de carbono orgânico, foram realizadas as determinações do teor de matéria orgânica pela mufla (descontados os teores de $\mathrm{CaCO}_{3}$ ), da solubilidade em pirofosfato de sódio, do teor de fibras esfregadas e do grau de decomposição pela escala de von Post (Embrapa, 2006). Em todos os solos, realizou-

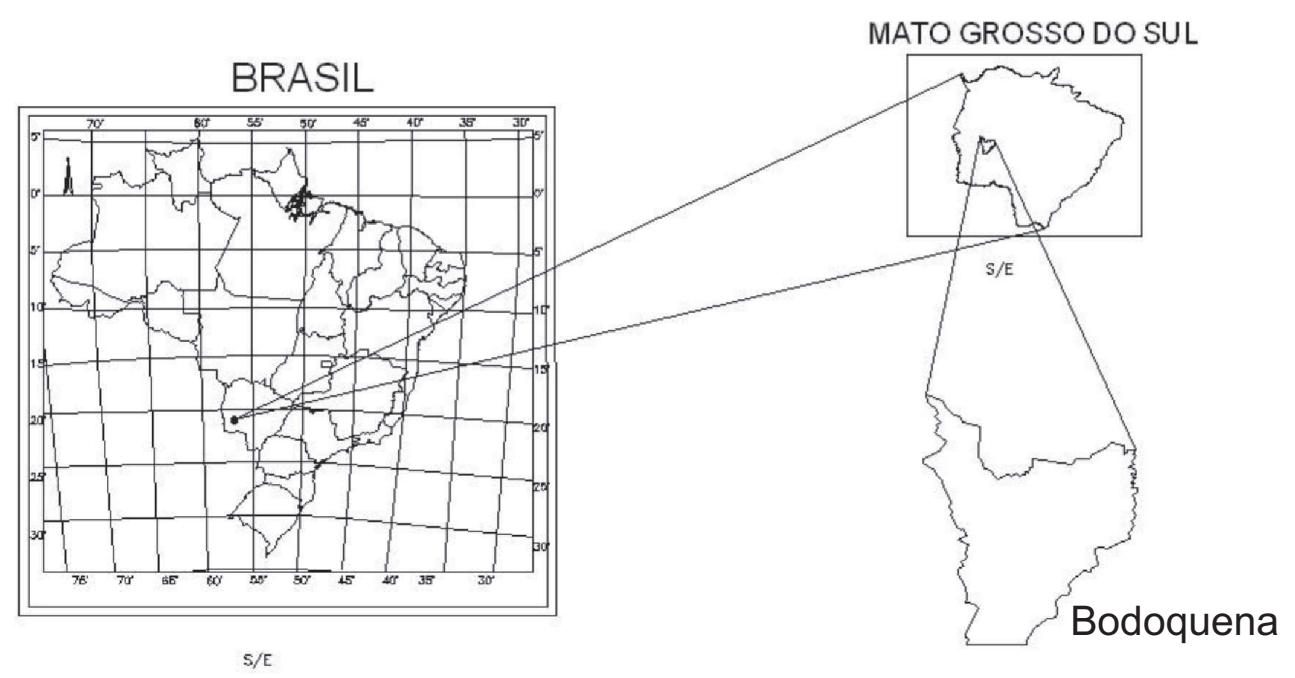

Figura 1. Localização do município de Bodoquena, MS. 
Quadro 1. Informações gerais dos solos da topossequência

\begin{tabular}{|c|c|c|c|c|c|c|c|c|}
\hline Perfil & $\begin{array}{l}\text { Coord. } \\
\text { (UTM) }\end{array}$ & $\begin{array}{l}\text { Situação } \\
\text { paisagem }\end{array}$ & $\begin{array}{c}\text { Relevo } \\
\text { local }\end{array}$ & $\begin{array}{c}\text { Material de } \\
\text { origem }\end{array}$ & $\begin{array}{c}\text { Vegetação } \\
\text { atual }\end{array}$ & Alt. (m) & Drenagem & $\begin{array}{c}\text { Pedregosidade } \\
\text { e rochosidade }\end{array}$ \\
\hline $\mathrm{P} 1$ & $\begin{array}{c}21 \mathrm{~K} \\
0530668 / \\
7723991\end{array}$ & $\begin{array}{l}\text { Topo de } \\
\text { elevação }\end{array}$ & $\begin{array}{c}\text { Forte } \\
\text { ondulado }\end{array}$ & $\begin{array}{c}\text { Produto da } \\
\text { intemperização } \\
\text { de calcários } \\
\text { e orgânicos }\end{array}$ & $\begin{array}{l}\text { Cerrado em } \\
\text { regeneração }\end{array}$ & 350 & Bem drenado & $\begin{array}{c}\text { Extremamente } \\
\text { pedregosa e } \\
\text { muito rochosa }\end{array}$ \\
\hline $\mathrm{P} 2$ & $\begin{array}{c}21 \mathrm{~K} \\
0530610 / \\
7724121\end{array}$ & Terço inferior & $\begin{array}{c}\text { Suave } \\
\text { ondulado }\end{array}$ & $\begin{array}{c}\text { Produto da } \\
\text { intemperização } \\
\text { de calcários }\end{array}$ & Pastagem & 324 & Bem drenado & $\begin{array}{l}\text { Rochosa a partir } \\
\text { do horizonte } \mathrm{Bi} 2\end{array}$ \\
\hline P3 & $\begin{array}{c}21 \mathrm{~K} \\
0530552 / \\
7724154\end{array}$ & $\begin{array}{l}\text { Sopé da } \\
\text { encosta }\end{array}$ & Plano & $\begin{array}{c}\text { Produto da } \\
\text { intemperização } \\
\text { de calcários }\end{array}$ & Pastagem & 323 & Bem drenado & Ausente \\
\hline $\mathrm{P} 4$ & $\begin{array}{c}21 \mathrm{~K} \\
0530344 / \\
7724206\end{array}$ & Baixada & Plano & $\begin{array}{c}\text { Sedimentos } \\
\text { aluviais e } \\
\text { coluviais }\end{array}$ & Pastagem & 309 & $\begin{array}{l}\text { Mal drenado } \\
\text { (lençol freático } \\
\text { a } 50 \mathrm{~cm} \text { ) }\end{array}$ & Ausente \\
\hline P5 & $\begin{array}{c}21 \mathrm{~K} \\
0530347 / \\
7724154\end{array}$ & Baixada & Plano & $\begin{array}{l}\text { Sedimentos } \\
\text { aluviais } \\
\text { e orgânicos }\end{array}$ & Floresta & 310 & $\begin{array}{l}\text { Muito mal drenado } \\
\text { (lençol freático } \\
\text { a } 50 \mathrm{~cm} \text { ) }\end{array}$ & Ausente \\
\hline
\end{tabular}

Coord.: coordenada; Alt.: altitude.

se o fracionamento químico da matéria orgânica (frações húmicas), utilizando o método proposto por Benites et al. (2003).

Os minerais da fração argila foram identificados por difração de raios-X (DRX), em lâminas orientadas, montadas com suspensão de argila total $(<2,0 \mu \mathrm{m})$, sem eliminação de óxidos de Fe (Embrapa, 1997). As análises foram realizadas em difratômetro Bruker AXS, modelo D8 Advance, empregando-se radiação de $\mathrm{K} \alpha$ de $\lambda 0,015405 \mathrm{~nm}$, produzida por tubo de cobre, 40 $\mathrm{kv}$ e $40 \mathrm{~mA}$, com amplitude de varredura de 3 a $70^{\circ} 2 \theta$ e velocidade de $1^{\circ} 2 \theta$ por $\min \left(0,04^{\circ} / \mathrm{s}\right)$. Para as amostras com indicação de presença de minerais $2: 1$, foram feitos os pré-tratamentos: aquecimento a $550^{\circ} \mathrm{C}$, saturação com etilenoglicol e dimetilsulfóxido, com posterior irradiação pelos raios-X. As amostras da fração areia foram previamente moídas em moinho de bolas para obtenção do pó cristalino. Posteriormente, realizou-se a difração de raios-X (DRX) em pó não orientado, sendo utilizado o mesmo equipamento empregado para a identificação dos minerais da fração argila.

A partir dos atributos morfológicos, físicos, químicos e mineralógicos, os solos foram classificados de acordo com o Sistema Brasileiro de Classificação de Solos - SiBCS (Santos et al., 2006).

\section{RESULTADOS E DISCUSSÃO}

\section{Gênese e classificação}

A variação dos perfis ao longo da topossequência esta intimamente relacionada com o relevo que condiciona a drenagem e o escoamento superficial. O material de origem, de natureza calcária, é o mesmo em toda a topossequência, com contribuições de materiais coluviais, em razão da posição no relevo.

Entre os processos de formação mais atuantes na formação dos solos, podem ser citados: deposição e acumulação de serapilheira, na formação do horizonte $\mathrm{O}$ hístico do perfil $\mathrm{P} 1$; melanização, no desenvolvimento de A chernozêmico dos perfis P2, P3 e P4; paludização, na formação do $\mathrm{H}$ hístico do perfil P5; gleização, na formação dos horizontes $\mathrm{C}$ glei nos perfis P4 e P5; e carbonatação, com a formação de carbonatos secundários em todos os perfis.

A elevada estabilidade da matéria orgânica, nesse caso, é favorecida pelos elevados teores de $\mathrm{Ca}^{2+}$, formando pontes entre a fração mineral e os grupos funcionais reativos e ionizados na matéria orgânica, o que propicia proteção e consequentemente redução da decomposição/mineralização da matéria orgânica depositada, com acúmulo na superfície do solo.

Quanto à classificação dos solos segundo o SiBCS, o perfil $\mathrm{P} 1$ (OOs), com a sequência de horizontes O-R e o teor de carbono orgânico de $140,4 \mathrm{~g} \mathrm{~kg}^{-1}$, tem constituição orgânica associada à condição de drenagem livre, sendo identificado como O hístico. Essa associação de atributos fez com que o perfil de solo fosse identificado como Organossolo Fólico. Por meio da análise da cor determinada pelo método do pirofosfato de sódio, verificou-se a cor brunoacinzentada muito escura (10 YR 3/3), que define material fortemente decomposto pelo grau de decomposição de von Post. Em relação ao teor de fibras 
esfregadas (15\%), o material orgânico do horizonte O foi classificado como Sáprico no terceiro nível categórico. Já em nível de subgrupo, o perfil foi identificado como lítico, por apresentar contato lítico dentro de $50 \mathrm{~cm}$ da superfície.

Os perfis P2 (MXo), com uma sequência de horizontes A-Bi, e P3 (MTo), com horizontes A-Bt, apresentaram horizonte diagnóstico superficial A chernozêmico, associado a horizontes subsuperficiais com argila de atividade alta ( $\mathrm{Ta}$ ) e alta saturação por bases, o que os identifica no nível categórico de ordem como Chernossolos. Quanto à subordem, o perfil P2 foi classificado como Háplico e o P3, que possui um horizonte $\mathrm{B}$ textural Ta, foi identificado como Argilúvico. Ambos os perfis foram classificados nos níveis de grande grupo e subgrupo como Órticos típicos.

Os perfis P4 e P5 (GMk), com horizontes A-Cḱg, localizados na baixada com drenagem impedida, foram enquadrados na ordem dos Gleissolos. Ambos os perfis foram classificados no nível de subordem como Melânicos por apresentarem um horizonte diagnóstico superficial A chernozêmico e $\mathrm{H}$ hístico, respectivamente. Para esses perfis, foram observados valores de carbonato de cálcio superiores a $150 \mathrm{~g} \mathrm{~kg}^{-1}$, o que indica a ocorrência do caráter Carbonático, atributo utilizado para a categorização no nível de grande grupo. Já no nível de subgrupo, os perfis foram identificados como chernossólicos e organossólicos, respectivamente, por apresentarem horizontes superficiais chernozêmico e hístico.

\section{Atributos morfológicos}

Em todos os perfis, os horizontes superficiais apresentaram cores escuras, com predomínio de cores neutras (N 2/), acromáticas (Quadro 2), sendo esse padrão decorrente da associação do carbono orgânico com o íon cálcio, levando à formação de humatos de cálcio (Duchaufour, 1982), o que confere maior estabilidade à matéria orgânica. Nos perfis localizados nos pontos mais baixos da topossequência (GMk1 e GMk2), além dos fatores apresentados anteriormente, as condições de drenagem impedida desfavorecem a decomposição da matéria orgânica, contribuindo para o escurecimento dos horizontes superficiais.

Estudando a influência do lençol freático na morfologia de Mollisols no Irã, Abtahi \& Khormali (2001) verificaram padrão similar para os horizontes superficiais, onde as condições de anaerobiose impostas pelo lençol retardaram a decomposição da matéria orgânica, promovendo maior escurecimento desses horizontes.

Para os horizontes subsuperficiais, nos perfis MXo e MTo, foram observadas cores bruno-avermelhadas, com predomínio do matiz 5YR, em MXo, e 2,5YR, MTo, que são decorrentes da boa condição de drenagem (Quadro 2). Para os perfis GMk1 e GMk2, as cores acinzentadas, N3/ e N2/, respectivamente, são reflexo do ambiente reductomórfico, que favorece a redução e remoção do $\mathrm{Fe}$ do solo. Esse padrão também foi verificado por Santos et al. (2010) em perfil localizado em área plana de várzea em Pinheiral (RJ), onde esses autores atribuíram as cores acinzentadas ao predomínio das condições de hidromorfismo observadas na área.

Quanto à estrutura, o formato granular evidenciouse nos horizontes superficiais, com tamanho variável de muito pequena a grande e grau de desenvolvimento variando de fraco a forte. Nos horizontes subsuperficiais, foram observadas estruturas geralmente em blocos ou prismáticas composta por blocos angulares, verificadas nos perfis MXo e MTo (Quadro 2). Nos perfis GMk1 e GMk2, em razão da condição de drenagem impedida, foi observada a estrutura maciça.

Estudando perfis de solos formados a partir de material de natureza calcária, Souza et al. (1993) observaram estrutura fortemente desenvolvida, do tipo prismático e em blocos, como ocorre normalmente nos solos com maior influência de calcário. Shinzato (1998), em estudos com solos formados a partir de materiais de origem da mesma natureza, notou que os perfis apresentaram, em sua maioria, estrutura no horizonte B em blocos subangulares, angulares e granulares, com moderado grau de desenvolvimento e tamanho pequeno a médio, evidenciando-se a grande variabilidade estrutural que esses solos podem apresentar.

No perfil MTo, foi observada a ocorrência de cerosidade nos horizontes $\mathrm{Bt}_{1}, \mathrm{Bt}_{2}$ e $\mathrm{BC}$ (Quadro 2), o que demonstra a ocorrência de iluviação de argila e determina o caráter argilúvico para esses horizontes.

Quanto ao grau de decomposição da matéria orgânica avaliada, para o horizonte $\mathrm{O}(\mathrm{OOS})$ foi observada a cor 10YR 3/3 e para o Hḱ (GMk2), 10YR $3 / 4$, determinadas pelo pirofostato de sódio, sendo os horizontes classificados com o grau de decomposição sáprico. Para o grau de decomposição de von Post, o horizonte $\mathrm{O}(\mathrm{OOs})$ foi classificado como muito fortemente decomposto e o Hḱ (GMk2), como fortemente decomposto, não sendo identificável a estrutura vegetal original. Quanto ao teor de fibras esfregadas, esse foi inferior a $17 \%$, em ambos os horizontes; $15 \%$, em (OOs); e $10 \%$, em Hḱ.

\section{Atributos físicos}

A análise granulométrica dos solos evidencia teores de argila variando entre 240 a $700 \mathrm{~g} \mathrm{~kg}^{-1}$ (Quadro 3). De maneira geral, os valores da argila tendem a aumentar nos horizontes $\mathrm{B}$, diminuindo à medida que se aproxima do material de origem ou a partir do $\mathrm{A}$, nos casos de sequência A-C. Para os perfis que apresentam sequência de horizontes $A-B$, não foi constatada a presença de gradiente textural, apesar de o perfil MTo apresentar caráter argilúvico (gradiente textural de 1,47 e cerosidade) (Embrapa, 2006). 
Quadro 2. Distribuição dos horizontes e atributos morfológicos dos solos em topossequência

\begin{tabular}{|c|c|c|c|c|c|c|}
\hline \multirow[t]{2}{*}{ Perfil } & \multirow[t]{2}{*}{ Horizonte } & \multirow{2}{*}{$\begin{array}{c}\text { Profundidade } \\
(\mathrm{cm})\end{array}$} & \multicolumn{2}{|c|}{ Cor } & \multirow[t]{2}{*}{ Estrutura $^{(1)}$} & \multirow[t]{2}{*}{ Cerosidade $^{(2)}$} \\
\hline & & & seca & úmida & & \\
\hline \multicolumn{7}{|c|}{ Organossolo Fólico Sáprico lítico - OOs } \\
\hline $\mathrm{P} 1$ & Od & $0-23$ & $5 Y 2,5 / 1$ & $\mathrm{~N} 2 /$ & fr. pq. gr & - \\
\hline $\mathrm{P} 1$ & $\mathrm{R}$ & - & - & - & rocha calcária & - \\
\hline \multicolumn{7}{|c|}{ Chernossolo Háplico Órtico típico - MXo } \\
\hline $\mathrm{P} 2$ & $\mathrm{~A} 1$ & $0-10$ & $2,5 \mathrm{Y} 2,5 / 1$ & $\mathrm{~N} 2 /$ & mo., gra. e gr & - \\
\hline $\mathrm{P} 2$ & $\mathrm{~A} 2$ & $10-23$ & $2,5 \mathrm{Y} 2,5 / 1$ & $\mathrm{~N} 2 /$ & mo., gra. e gr & \\
\hline $\mathrm{P} 2$ & $\mathrm{AB}$ & $23-32$ & $2,5 \mathrm{Y} 2,5 / 1$ & $\mathrm{~N} 2 /$ & mo., gra. e gr & \\
\hline $\mathrm{P} 2$ & BA & $32-41$ & $5 Y R 3 / 1$ & $5 Y R 3 / 1$ & mo., pe. e me, gr., bsa. & \\
\hline $\mathrm{P} 2$ & Bi1 & $41-60$ & $5 \mathrm{YR} 3 / 1$ & $5 \mathrm{YR} 3 / 2$ & fo., pe., ba. & \\
\hline $\mathrm{P} 2$ & $\mathrm{Bi} 2$ & $60-78^{+}$ & $5 Y R 3 / 2$ & $5 \mathrm{YR} 3 / 2$ & mo., pq. pr. e fo., pe., ba. & - \\
\hline \multicolumn{7}{|c|}{ Chernossolo Argilúvico Órtico típico - MTo } \\
\hline P3 & $\mathrm{A} 1$ & $0-14$ & 2,5 Y $3 / 2$ & $\mathrm{~N} 2 /$ & mo., gr. e gra. & - \\
\hline P3 & $\mathrm{A} 2$ & $14-24$ & $5 \mathrm{Y} 3 / 2$ & $5 Y R \quad 3 / 1$ & mo., gr. e gra e fo., me e bsa & - \\
\hline P3 & $\mathrm{AB}$ & $24-32$ & $2,5 \mathrm{Y} 4 / 3$ & 5 YR $2,5 / 2$ & fo., pe e ba & po. e mo. \\
\hline P3 & BA & $32-42$ & $10 \mathrm{YR} 3 / 4$ & $2,5 \mathrm{YR} 2 / 4$ & fo., pe e ba & fo. e co. \\
\hline P3 & Bt1 & $42-67$ & 2,5 YR 3/3 & $2,5 \mathrm{YR} 3 / 4$ & fo., me. e pr e fo., me. e ba. & fo. e $a b$. \\
\hline P3 & Bt2 & $67-94$ & $5 \mathrm{YR} 4 / 4$ & $2,5 \mathrm{YR} 3 / 4$ & fo., me. e pr e fo., me. e ba. & fo. e ab. \\
\hline P3 & $\mathrm{BC}$ & $94-118^{+}$ & 2,5 YR $4 / 4$ & $2,5 \mathrm{YR} 3 / 4$ & fo., pe. e me., ba. & fo. e ab. \\
\hline \multicolumn{7}{|c|}{ Gleissolo Melânico Carbonático chernossólico - GMk1 } \\
\hline $\mathrm{P} 4$ & $\mathrm{~A}$ & $0-33$ & $5 \mathrm{Y} 3 / 1$ & $\mathrm{~N} 2 /$ & fo., pq., gr. & - \\
\hline $\mathrm{P} 4$ & $\mathrm{Cg}$ & $33-48$ & 5 Y $4 / 3$ & N 3/ & maciça & - \\
\hline $\mathrm{P} 4$ & Cḱg1 & $48-68$ & $5 \mathrm{Y} 5 / 4$ & $\mathrm{~N} 3 /$ & maciça & - \\
\hline $\mathrm{P} 4$ & Cḱg2 & $68-88^{+}$ & $5 \mathrm{Y} 5 / 4$ & N 3/ & maçica & - \\
\hline \multicolumn{7}{|c|}{ Gleissolo Melânico Carbonático organossólico - GMk2 } \\
\hline P5 & $\mathrm{Hk}$ & $0-30$ & 5 Y $2,5 / 2$ & $\mathrm{~N} 2 /$ & fo., mpq., gr. & - \\
\hline P5 & Cḱg & $30-60^{+}$ & $5 \mathrm{Y} 6 / 2$ & $\mathrm{~N} 2 /$ & maciça & - \\
\hline
\end{tabular}

${ }^{(1)} \mathrm{fr}=$ fraca; ${ }^{(1)} \mathrm{mo}=\operatorname{moderada} ;{ }^{(1)} \mathrm{fo}=$ forte $;{ }^{(1)} \mathrm{mpq}=$ muito pequena; ${ }^{(1)} \mathrm{pq}=$ pequena; ${ }^{(1)} \mathrm{me}=\mathrm{média} ;{ }^{(1)} \mathrm{gr}=$ grande ${ }^{(1)} \mathrm{ba}=\mathrm{blocos}$ angulares; ${ }^{(1)} \mathrm{bsa}=$ blocos subangulares; ${ }^{(1)} \mathrm{gr}=$ granular; ${ }^{(2)}$ po = pouco; ${ }^{(2)}$ co $=$ comum; e ${ }^{(2)} \mathrm{ab}=\mathrm{abundante}$.

Verifica-se o predomínio da fração areia grossa em relação à areia fina, em todos os perfis estudados. Os valores de silte foram elevados, variando entre 180 a $560 \mathrm{~g} \mathrm{~kg}^{-1}$. Quanto à relação silte/argila, essa apresentou variação irregular, sendo os menores valores observados no perfil MTo, indicando que esse perfil apresenta o maior grau de transformação quando comparado aos demais. Segundo Santos et al. (2006), valores inferiores a 0,6 , em horizontes que apresentam textura argilosa, indicam elevado grau de intemperismo; entretanto, essa relação não é aplicável a solos cujos materiais de origem tenham natureza sedimentar como o próprio calcário, o arenito ou o siltito (Shinzato, 1998).

De modo geral, todos os horizontes minerais apresentaram elevados valores de argila dispersa, sendo exceção os $\mathrm{A} 1, \mathrm{~A} 2$ e $\mathrm{Bi}_{2}$ do perfil MXo, concomitante com o baixo grau de floculação (GF) (Quadro 3). Um possível fator para a elevada dispersão desses solos são os elevados valores de $\mathrm{Ca}^{2+}$ e de $\mathrm{pH}$. No perfil MTo, o baixo GF nos horizontes superficiais favorece a translocação das argilas e, consequentemente, a formação da cerosidade em subsuperfície.

Os valores de Ds variaram de 0,50 a $1,40 \mathrm{Mg} \mathrm{m}^{-3}$, sendo os menores valores observados nos horizontes superficiais, em razão dos maiores teores de matéria orgânica. Em todos os perfis, onde foram coletadas amostras para a quantificação da Ds, foi observado aumento desse atributo em profundidade. Os maiores valores de Ds foram verificados nos horizontes subsuperficiais dos perfis MXo (Bi1) e MTo (Bt2 e Bt3) e podem ser decorrentes dos maiores teores de argila nesses horizontes, associados à pressão exercida pelos horizontes superiores.

\section{Atributos químicos}

Para todos os perfis, observaram-se elevados valores de $\mathrm{pH}$, entre 7,2 e 8,6, decorrentes da influência do material de origem, não sendo verificada grande variação de $\mathrm{pH}$ entre horizontes (Quadro 4). Quanto à reação do solo, todos os perfis foram classificados como 
Quadro 3. Atributos físicos dos solos da topossequência

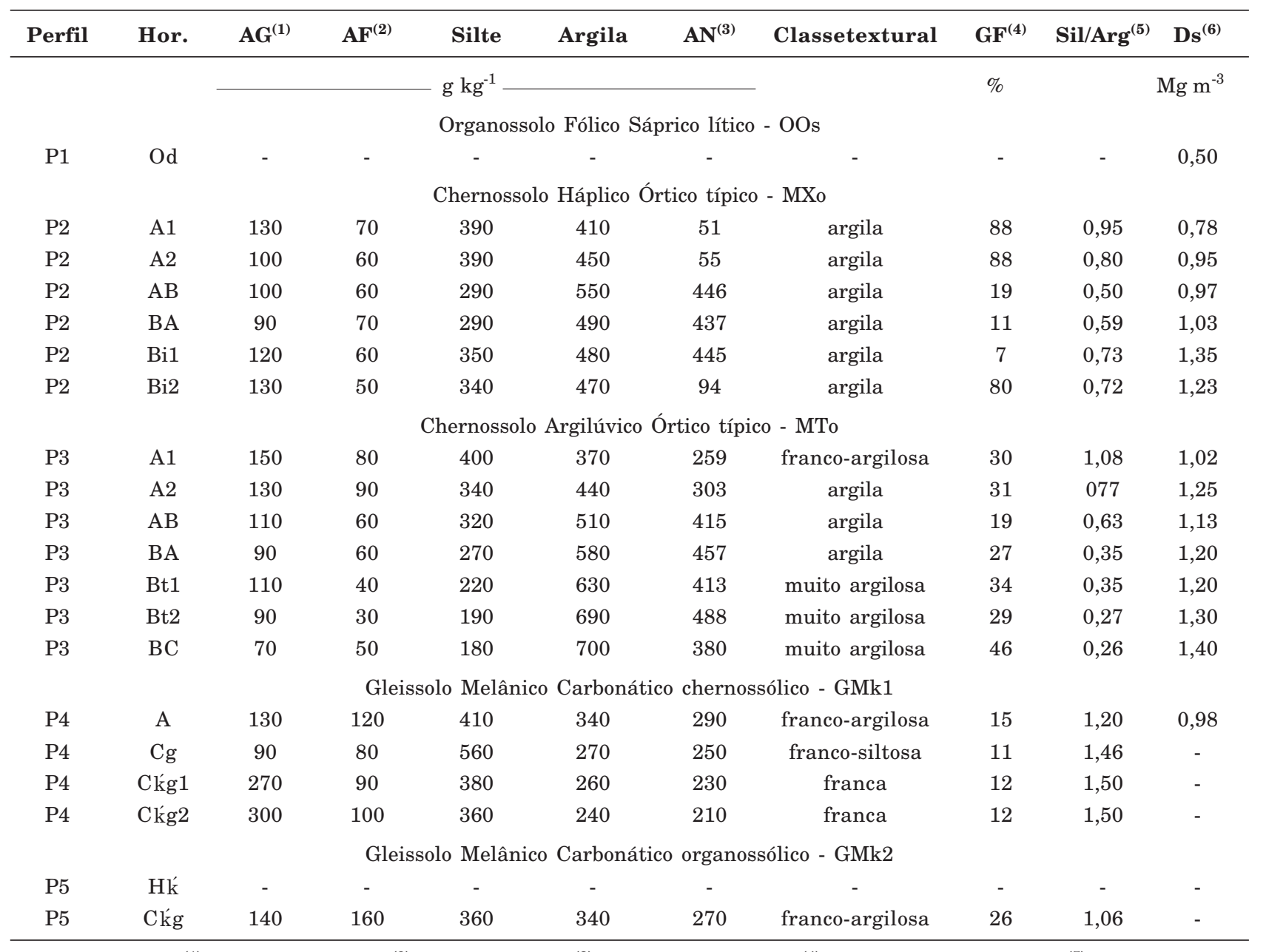

Hor. = horizonte; ${ }^{(1)} \mathrm{AG}=$ areia grossa; ${ }^{(2)} \mathrm{AF}=$ areia fina; ${ }^{(3)} \mathrm{AN}=$ argila natural; ${ }^{(4)} \mathrm{GF}$ = grau de floculação; ${ }^{(5)} \mathrm{Sil} / \mathrm{Arg}=$ relação silte/argila; ${ }^{(6)} \mathrm{Ds}=$ densidade do solo.

de reação moderada a fortemente alcalina (Embrapa, 2006). Ao longo da topossequência, verificou-se que os maiores valores de $\mathrm{pH}$ ocorrem nos perfis GMk1 e GMk2, localizados na baixada, indicando a lixiviação e acumulação de cálcio nas partes mais baixas da topossequência, fato comprovado por esses perfis apresentarem os maiores valores de $\mathrm{Ca}$ e $\mathrm{CaCO}_{3}$.

Os valores de $\mathrm{pH}$ obtidos são concordantes com aqueles observados por Ramos \& Manzatto (1991), Souza et al. (1993) e Owliaie et al. (2005), em estudos com solos de natureza calcária, que verificaram valores de $\mathrm{pH}$ sempre superiores a 7,0, sendo comum valores variando entre 8,0 e 8,5.

Nas bases trocáveis, o $\mathrm{Ca}^{2+}$, juntamente com o $\mathrm{Mg}^{2+}$, foram os cátions predominantes no complexo sortivo, seus valores variaram entre 14,3 e $42,7 \mathrm{cmol}_{\mathrm{c}}$ $\mathrm{kg}^{-1}$ e 0,7 e $9,9 \mathrm{cmol}_{\mathrm{c}} \mathrm{kg}^{-1}$, para o $\mathrm{Ca}^{2+}{\mathrm{e} \mathrm{Mg}^{2+}}^{2+}$ respectivamente (Quadro 4). Com relação ao $\mathrm{K}^{+}$, evidenciaram-se valores médios a altos, variando entre 0,18 e $2,09 \mathrm{cmol}_{\mathrm{c}} \mathrm{kg}^{-1}$. Todos os íons constituintes do complexo sortivo decrescem com a profundidade.
Os valores da soma de bases (SB) variaram entre 17,4 e $47,6 \mathrm{cmol}_{\mathrm{c}} \mathrm{kg}^{-1}$ (Quadro 4) e os de saturação por bases (V) foram elevados acima de $90 \%$, o que contribuiu para os altos valores de $\mathrm{pH}$ em água. Quanto aos teores de carbonatos de cálcio de OOs, MXo e MTo, esses variaram entre 50 e $150 \mathrm{~g} \mathrm{~kg}^{-1}$, sendo atribuído a esses perfis o caráter com carbonato (Embrapa, 2006). Os menores valores de carbonato observados podem ser decorrentes da melhor drenagem dos perfis, o que favorece a sua solubililização e lixiviação na forma de bicarbonato de cálcio. Já os perfis GMk1 e GMk2, localizados na baixada, posição essa que favorece a adição dos íons das partes mais altas e diminuição das perdas por lixiviação, em razão da condição de drenagem impedida, apresentaram caráter carbonático e valores de $\mathrm{CaCO}_{3}$ acima de $150 \mathrm{~g} \mathrm{~kg}^{-1}$.

Com exceção do perfil OOs, que apresentou um único horizonte de constituição orgânica, todos os demais solos apresentaram valores de CTC da fração argila acima de $27,0 \mathrm{cmol}_{\mathrm{c}} \mathrm{kg}^{-1}$ (Quadro 4), o que indica 
Quadro 4. Atributos químicos dos solos da topossequência

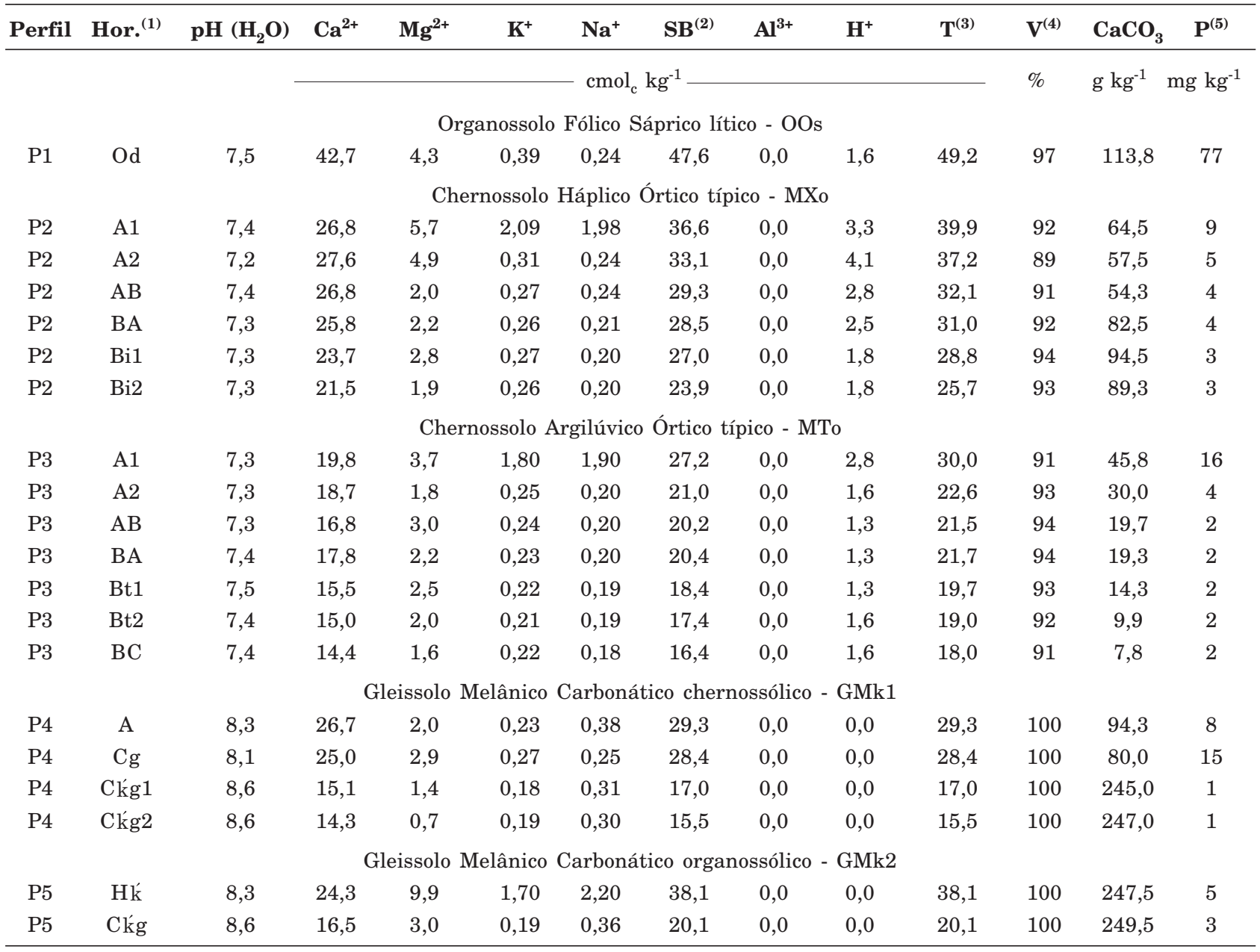

(1) Hor. = horizonte; ${ }^{(2)} \mathrm{SB}=$ soma de bases; ${ }^{(3)} \mathrm{T}=\mathrm{CTC}$ a pH 7,$0 ;{ }^{(4)} \mathrm{V}=$ saturação por bases; ${ }^{(5)} \mathrm{P}=$ fósforo assimilável.

o predomínio de argilas do tipo 2:1, decorrentes da natureza do material de origem. Estudando solos de origem calcária na região do Baixo de Irecê, na Bahia, Vertissolos e Cambissolos vérticos carbonáticos, Souza et al. (1993) também encontraram elevados valores de CTC da fração argila, da ordem de 60,0 a 70,0 $\mathrm{cmol}_{\mathrm{c}}$ $\mathrm{kg}^{-1}$, que foram atribuídos à natureza calcária dos solos.

Os valores dos elementos pelo ataque sulfúrico indicam que os valores da relação ki estiveram entre 0,40 e 2,27 e os da relação kr entre 0,27 e 1,79, ambas para os perfis GMk2 e (OOs) (Quadro 5). Apesar de os baixos valores de ki e kr sugerirem elevado grau de pedogênese, esse atributo parece não estar em consonância com os demais examinados no perfil do solo (CTC da argila, estrutura, mineralogia da fração argila, entre outros). Os baixos valores de ki parecem ser decorrentes da natureza do material de origem sedimentar.

\section{Carbono orgânico e frações húmicas}

Para todos os perfis, verificou-se o decréscimo dos valores de carbono orgânico (CO) em profundidade.
Os horizontes superficiais dos perfis OOs e GMk2 apresentaram valores de $\mathrm{CO}$ superiores a $80,0 \mathrm{~g} \mathrm{~kg}^{-1}$ (Quadro 6), valores que indicam que esses horizontes são de constituição orgânica (Embrapa, 2006). Por causa da diferença de drenagem e do ponto da topossequência onde os perfis estão localizados, os horizontes foram classificados como $\mathrm{O}$ hístico no perfil OOs e H hístico, no GMk2. Todos os demais horizontes apresentaram valores de $\mathrm{C}$ inferiores a $80,0 \mathrm{~g} \mathrm{~kg}^{-1}$, sendo de constituição mineral.

A distribuição das frações húmicas apresentou o mesmo padrão observado para o $\mathrm{CO}$, com decréscimo em profundidade (Quadro 6). Para o perfil OOs, aproximadamente $64 \%$ do CO encontra-se na forma de frações húmicas, indicando baixa solubilidade da matéria orgânica. Os ácidos húmicos representaram os menores teores entre as frações húmicas, apenas $2 \%$; a humina, os maiores teores, sendo superior a $93 \%$. Na soma das frações alcalino-solúveis $(\mathrm{C}-\mathrm{FAF}+\mathrm{C}-$ FAH) encontra-se apenas $7 \%$ do CO.

De maneira semelhante, MXo e MTo também apresentaram decréscimo no $\mathrm{CO}$ e nas frações húmicas 
em profundidade. No perfil MXo, observou-se que a frações húmicas representam de 65 a $75 \%$ do CO. Já no GMk1, essa percentagem foi maior, variando de 71 a $91 \%$. No entanto, em ambos os solos, a humina foi a fração predominante. Nos perfis MXo e MTo, os teores dos ácidos húmicos no horizonte superficial foram maiores, o que contribuiu para aumento da relação C-FAH/C-FAF.
No perfil GMk1, localizado do terço inferior da topossequência, as frações húmicas representaram de 72 a $97 \%$ do CO; entretanto, no perfil GMk2, essa percentagem foi menor, entre 49 e $70 \%$. De forma semelhante aos outros solos da topossequência, a humina predominou nos perfis GMk1 e GMk2.

O predomínio da humina em solos com elevados conteúdos de carbonato foi relatado por Volkoff \& Cerri

Quadro 5. Elementos determinados pelo ataque sulfúrico de horizontes selecionados

\begin{tabular}{|c|c|c|c|c|c|c|c|}
\hline Perfil & Hor. ${ }^{(1)}$ & $\mathrm{SiO}_{2}$ & $\mathbf{A l}_{2} \mathbf{O}_{3}$ & $\mathrm{Fe}_{2} \mathrm{O}_{3}$ & $\mathrm{TiO}_{2}$ & $\mathbf{k i}^{(2)}$ & $\mathbf{k r}^{(3)}$ \\
\hline Organossolo Fólico Sáprico lítico - OOs & Od & 144 & 108 & 45 & 3,8 & 2,27 & 1,79 \\
\hline Chernossolo Háplico Órtico típico - MXo & Bt2 & 213 & 210 & 63 & 6,9 & 1,72 & 1,45 \\
\hline Chernossolo Argilúvico Órtico típico - MTo & $\mathrm{Bt} 2$ & 209 & 199 & 78 & 4,2 & 1,78 & 1,44 \\
\hline Gleissolo Melânico Carbonático chernossólico - GMk1 & $\mathrm{Cg}$ & 126,0 & 135 & 42 & 2,8 & 1,59 & 1,32 \\
\hline Gleissolo Melânico Carbonático organossólico - GMk2 & $\mathrm{C} 1 \mathrm{~g}$ & 4,0 & 17 & 13 & 1,0 & 0,40 & 0,27 \\
\hline
\end{tabular}

(1) Hor.= horizonte; ${ }^{(2)} \mathrm{ki}=\left(\mathrm{SiO}_{2} / \mathrm{Al}_{2} \mathrm{O}_{3}\right) \times 1,7 ;{ }^{(3)} \mathrm{kr}=\left(\mathrm{SiO}_{2} \times 1,7\right) /\left(\mathrm{Al}_{2} \mathrm{O}_{3}+\left(0,64 \times \mathrm{Fe}_{2} \mathrm{O}_{3}\right)\right)$.

Quadro 6. Carbono orgânico e frações húmicas dos solos da topossequência

\begin{tabular}{|c|c|c|c|c|c|c|c|}
\hline Perfil & Horizonte & $\mathbf{C O}^{(1)}$ & $\mathbf{C}-\mathbf{A F}^{(2)}$ & $\mathbf{C}-\mathbf{A H}^{(3)}$ & C-HUM $M^{(4)}$ & C-AH/C-AF & C-EA/C-HUMM ${ }^{(5)}$ \\
\hline \multicolumn{8}{|c|}{$-\mathrm{g} \mathrm{kg}^{-1}$} \\
\hline \multicolumn{8}{|c|}{ Organossolo Fólico Sáprico lítico - OOs } \\
\hline $\mathrm{P} 1$ & Od & 140,4 & 2,8 & 1,4 & 62,8 & 0,5 & 0,07 \\
\hline \multicolumn{8}{|c|}{ Chernossolo Háplico Órtico típico - MXo } \\
\hline $\mathrm{P} 2$ & $\mathrm{~A} 1$ & 66,0 & 2,0 & 3,3 & 37,8 & 1,7 & 0,14 \\
\hline $\mathrm{P} 2$ & $\mathrm{~A} 2$ & 52,6 & 1,8 & 1,7 & 31,2 & 0,9 & 0,11 \\
\hline $\mathrm{P} 2$ & $\mathrm{AB}$ & 38,7 & 1,4 & 1,0 & 25,4 & 0,7 & 0,09 \\
\hline $\mathrm{P} 2$ & BA & 32,7 & 1,4 & 0,6 & 21,6 & 0,4 & 0,09 \\
\hline $\mathrm{P} 2$ & Bi1 & 26,7 & 1,2 & 0,3 & 18,4 & 0,3 & 0,08 \\
\hline P2 & $\mathrm{Bi} 2$ & 22,2 & 0,6 & 0,1 & 13,8 & 0,2 & 0,05 \\
\hline \multicolumn{8}{|c|}{ Chernossolo Argilúvico Órtico típico - MTo } \\
\hline P3 & $\mathrm{A} 1$ & 45,8 & 2,2 & 3,8 & 37,8 & 1,7 & 0,16 \\
\hline P3 & A2 & 30,0 & 1,6 & 1,0 & 23,4 & 0,6 & 0,11 \\
\hline P3 & $\mathrm{AB}$ & 19,7 & 1,5 & 0,7 & 15,8 & 0,5 & 0,14 \\
\hline P3 & BA & 19,3 & 1,7 & 0,5 & 11,5 & 0,3 & 0,19 \\
\hline P3 & Bt1 & 14,3 & 1,3 & 0,1 & 8,5 & 0,1 & 0,16 \\
\hline P3 & Bt2 & 9,9 & 1,1 & 0,2 & 6,8 & 0,2 & 0,19 \\
\hline P3 & $\mathrm{BC}$ & 7,8 & 0,4 & 0,5 & 5,7 & 1,3 & 0,16 \\
\hline \multicolumn{8}{|c|}{ Gleissolo Melânico Carbonático chernossólico - GMk1 } \\
\hline $\mathrm{P} 4$ & A & 51,0 & 2,2 & 1,2 & 37,8 & 0,6 & 0,09 \\
\hline $\mathrm{P} 4$ & $\mathrm{Cg}$ & 24,8 & 1,0 & 0,2 & 16,6 & 0,2 & 0,07 \\
\hline $\mathrm{P} 4$ & Cḱg1 & 6,5 & 0,1 & 0,1 & 6,1 & 1,0 & 0,03 \\
\hline $\mathrm{P} 4$ & Cḱg2 & 5,5 & 0,7 & 0,4 & 4,1 & 0,6 & 0,27 \\
\hline \multicolumn{8}{|c|}{ Gleissolo Melânico Carbonático organossólico - GMk2 } \\
\hline P5 & $\mathrm{Hk}$ & 111,7 & 4,0 & 3,0 & 85,8 & 0,8 & 0,08 \\
\hline P5 & Cḱg & 45,9 & 0,9 & 0,7 & 20,6 & 0,8 & 0,08 \\
\hline
\end{tabular}

(1) $\mathrm{CO}$ : carbono orgânico; ${ }^{(2)} \mathrm{C}-\mathrm{AF}$ : carbono na fração ácidos fúlvicos; ${ }^{(3)} \mathrm{C}-\mathrm{AH}$ : carbono na fração ácidos húmicos; ${ }^{4)} \mathrm{C}-\mathrm{HUM}$ : carbono na fração humina; ${ }^{(5)} \mathrm{C}-\mathrm{EA}$ : C-AF + C-AH. 
(1980), Cunha \& Ribeiro (1998), Miranda \& Ferreira (1999), Corrêa et al. (2003) e Fontana et al. (2010), o que é indicativo da elevada estabilidade da matéria orgânica nesses. Baixos valores da relação C-EA/CHUM nos horizontes superficiais definem o solo como de matéria orgânica estável (Fontana et al., 2010).

A elevada estabilidade da matéria orgânica nesses solos é atribuída à formação de pontes pelo cálcio e magnésio entre a matéria orgânica e os minerais de argila do tipo 2:1 (Duchaufour, 1977; Corrêa et al., 2003). Outros autores destacaram que o carbonato de cálcio presente no material de origem dos solos atua como floculante da matéria orgânica (Oades, 1988), onde as frações mais decompostas da matéria orgânica são precipitadas com o $\mathrm{Ca}^{2+}$, o que diminui a sua solubilidade (Muneer \& Oades, 1989).

Observou-se que os solos que apresentaram horizontes de constituição orgânica, Od (OOs) e H1 (GMk2), tiveram as menores percentagens das frações solúveis (C-FAF e C-FAH), quando comparados aos demais perfis. Uma possível explicação para o padrão observado pode ser atribuída aos elevados conteúdos de carbonato de cálcio que favorecem a maior estabilização da matéria orgânica, direcionado à maior formação de humina.

\section{Mineralogia das frações areia e argila}

Observou-se que a fração areia é essencialmente constituída por quartzo (Quadro 7), identificado pelos reflexos de 0,21; 0,24; 0,33; e $042 \mathrm{~nm}$. Em razão da intensidade dos reflexos, esse mineral deve ser o predominante. No perfil MTo, foi identificada a presença de piroxênio por meio de um reflexo de $0,23 \mathrm{~nm}$. Já a presença de calcita, nos GMk1 e GMk2, foi identificada por um reflexo de $0,30 \mathrm{~nm}$. A ocorrência desse mineral é corroborada pelos elevados teores de carbonato de cálcio que esses perfis apresentaram (Quadro 4).

Segundo Kämpf \& Curi (2012), os processos de precipitação da calcita são diferentes em solos bem drenados, em comparação aos mal drenados. Em solos mal drenados domina o fluxo ascendente da água, decorrente da evapotranspiração. O conteúdo relativamente elevado de água no subsolo limita a difusão gasosa, pelo qual a $\mathrm{P}_{\mathrm{CO}_{2}}$ é alta, decrescendo próximo à superfície do solo pela difusão do $\mathrm{CO}_{2}$ à atmosfera. Dessa forma, ocorre um fluxo ascendente de água, carreando consigo os íons $\mathrm{Ca}^{2+}{\mathrm{e} \mathrm{HCO}_{3}}^{-}$, que precipitam na superfície do solo onde a $\mathrm{P}_{\mathrm{CO}_{2}}$ é baixa e a solução do solo é concentrada por evaporação. A formação de calcita pedogênica nos perfís GMk1 e GMk2 pode ser decorrente da presença do íon oriundo da lixiviação das partes mais altas da topossequência e do bicarbonato.

Quanto à mineralogia da fração argila, no perfil MXo, horizonte $\mathrm{Bi}$, os principais minerais observados foram a montomorilonita, identificada por um pico de $1,31 \mathrm{~nm}$, que desaparece quando a amostra é submetida a aquecimento; illita (1,05 e 0,33 nm); caulinita $(0,73$ e $0,36 \mathrm{~nm})$; gibbsita $(0,49 \mathrm{~nm})$; e goethita $(0,40 \mathrm{~nm})$ (Figura 2$)$. Nesse perfil, verificouse menor definição dos picos da caulinita, o que sugere menor grau de cristalinidade desse mineral. Para o horizonte Bt2 do perfil MTo, notou-se a mesma composição mineralógica do horizonte $\mathrm{Bi} 2$ do perfil MXo, sendo exceção a presença da mica e da montomorilonita, o que sugere maior grau de intemperização do perfil.

Os perfis GMk1 e GMk2 apresentaram em comum, como principais minerais, a illita, identificada por reflexos de 1,08 e 0,33 nm; caulinita, 0,72 e 0,36 nm; gibbsita, 0,50nm; goethita, 0,43, 0,27 e 0,25 nm; e clorita, $0,20 \mathrm{~nm}$. No perfil GMk2, foi verificada a ocorrência de montmorilonita, identificada por um pico de 1,31 nm, que desaparece quando a amostra é submetida a aquecimento.

A caulinita formada nos perfis estudados pode ser produto tanto da alteração direta de outros minerais como pela recombinação do Si (em solução), liberado das lâminas tetraédricas dos argilominerais 2:1 com os hidróxidos de $\mathrm{Al}$ precipitados, permitindo a formação da caulinita no solo (Hus, 1989).

Verifica-se que, com exceção do perfil GMk1, todos os outros apresentaram minerais de argila $2: 1$. Para os perfis situados nas condições de melhor drenagem, a formação das argilas 2:1 é decorrente da transformação direta dos minerais primários presentes na fração areia. Para GMk2, que localiza-se na pior condição de drenagem, os minerais de argila 2:1 são formados por processos de lixiviação dos íons das partes mais altas da topossequência para as mais baixas, onde a restrição da drenagem favorece a precipitação desses, levando a neoformação de minerais de argila (Hus, 1989). Adicionalmente para o GMk2, a elevada saturação por cátions básicos, o pH próximo à neutralidade e a drenagem restrita favorecem a formação de argilas 2:1 (Borchardt, 1989).

Quadro 7. Mineralogia da fração areia dos horizontes selecionados

\begin{tabular}{lcc}
\hline \multicolumn{1}{c}{ Perfil } & Horizonte & Mineral observado \\
\hline Chernossolo Háplico Órtico típico - MXo & Bi2 & Quartzo >> muscovita \\
Chernossolo Argilúvico Órtico típico - MTo & Bt2 & Quarto >> piroxênio e muscovita \\
Gleissolo Melânico Carbonático chernossólico - GMk1 & Cg & Quartzo >> calcita e muscovita \\
Gleissolo Melânico Carbonático organossólico - GMk2 & Cḱg & Quartzo >> calcita e muscovita \\
\hline
\end{tabular}




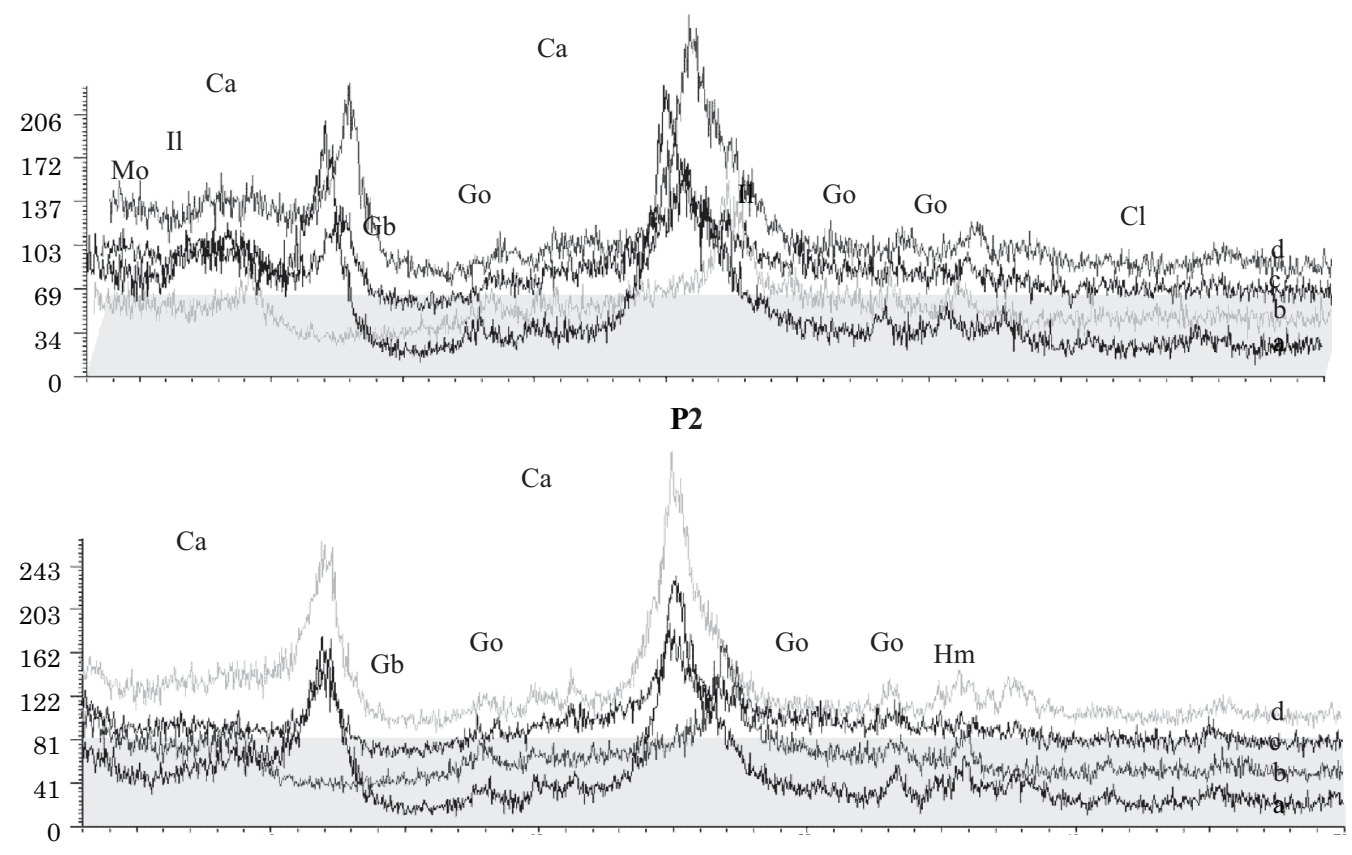

P3

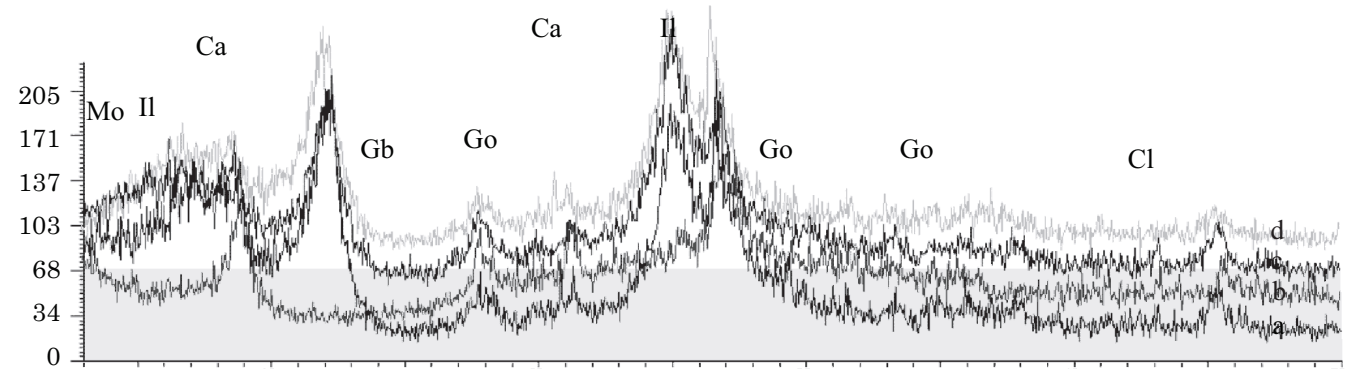

P4

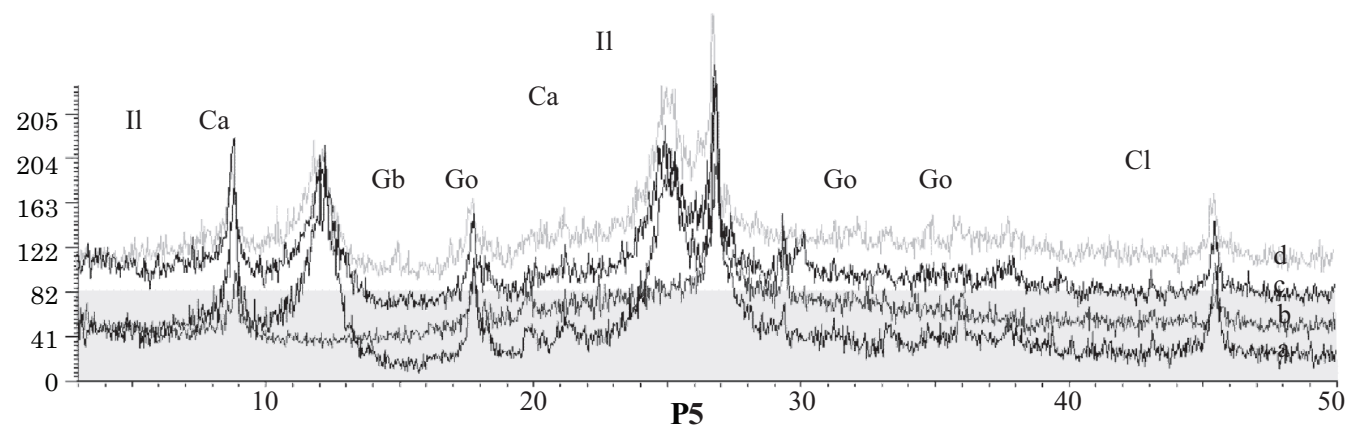

Figura 2. Difratograma de raios-X da fração argila dos perfis P2 (Bi2), P3 (Bt2), P4 (Cg) e P5 (Cḱg). Amostra seca ao ar (a); aquecimento a $550{ }^{\circ} \mathrm{C}$ (b); tratamento com dimetilsulfóxido (c); e tratamento com etilenoglicol (d). Mo=Montmorilonita; Mi=Mica; Il=Illita; Ca=Caulinita; Gb=Gibbsita; Go=Goethita; Hm=Hematita; e Cl=Clorita.

\section{CONCLUSÕES}

1. A variação dos solos na topossequência é determinada pelo relevo que condiciona a drenagem e o escoamento superficial.

2. Os elevados teores de carbono orgânico são condicionados pela interação entre a matéria orgânica depositada na superfície do solo e os íons cálcio, provendo a estabilização da matéria orgânica, o que pode ser constatado pelo predomínio absoluto da fração humina.

3. A ocorrência de Organossolo Fólico foi constatada em ambiente diferente de altimontamo, citado no SiBCS, sugerindo uma dispersão mais ampla desses solos. 


\section{LITERATURA CITADA}

ABTAHI, A. \& KHORMALI, F. Genesis and morphological characteristics of Mollisols formed in a catena under water table influence in southern Iran. Commun. Soil Plant Anal., 32:1643-1658, 2001.

ALMEIDA, F.F.M. Geologia da Serra da Bodoquena (MT). B. DNPM, 215/219:1-96, 1965.

BENITES, V.M.; MADARI, B. \& MACHADO, P.L.O.A. Extração e fracionamento quantitativo de substâncias húmicas do solo: Um procedimento simplificado de baixo custo. Rio de Janeiro, Embrapa Solos, 2003. 7p. (Embrapa Solos. Comunicado Técnico, 16)

BORCHARDT, G. Smectites. In: DIXON, J.B. \& WEED, S.B., eds. Minerals in soil environments. 2.ed. Madison, Soil Science Society of America, 1989. p.675-728.

CARVALHO JÚNIOR, O.A.C.; BERBET-BORN, M.; MARTINS, E.S.; GUIMARÃES, R.F. \& GOMES, R.A.T. Ambientes cársticos. In: FLORENZANO, T.G., ed. Geomorfologia conceitos e tecnologias atuais. São Paulo, Oficina de Textos, 2008. p.185-218.

CHEN, Y. \& BARAK, P. Iron nutrition of plants in calcareous soils. Adv. Agron., 35:217-240, 1982.

CORRÊA, M.M.; KER, J.C.; MENDONÇA, E.S.; RUIZ, H.A. \& BASTOS, R.S. Atributos físicos, químicos e mineralógicos de solos da região de várzeas de Souza (PB). R. Bras. Ci. Solo, 27:311-324, 2003.

CUNHA, T.J.F. \& RIBEIRO, L.P. Qualidade e relações pedogenéticas da matéria orgânica de alguns solos da região do Irecê (BA). R. Bras. Ci. Solo, 22:693-704, 1998.

DUCHAUFOUR, P. Pedology. London, George Allen \& Unwin Publication, 1977. 448p.

DUCHAUFOUR, P. Pedology: Pedogenesis and classification. London, George Allen \& Unwin, 1982. 187p.

EMPRESA BRASILEIRA DE PESQUISA AGROPECUÁRIA EMBRAPA. Centro Nacional de Pesquisa do Solo. Levantamento de reconhecimento dos solos do sul do Mato Grosso. Rio de Janeiro, 1971. 839p.

EMPRESA BRASILEIRA DE PESQUISA AGROPECUÁRIA EMBRAPA. Centro Nacional de Pesquisa do Solo Manual de métodos de análise de solos. Rio de Janeiro, 1997. $212 \mathrm{p}$.

FONTANA, A.; PEREIRA, M.G.; ANJOS, L.H.C. \& BENITES, V.M. Quantificação e utilização das frações húmicas como característica diferencial em horizontes diagnósticos de solos brasileiros. R. Bras. Ci. Solo, 34:1241-1257, 2010

HUS, P.H. Aluminium oxides and oxyhydroxides. In: DIXON, J.B. \& WEED, S.B., eds. Minerals in soil environments. 2.ed. Madison, Soil Science Society of America, 1989. p.331-378.
KÄMPF, N. \& CURI, N. Formação e evolução do solo (Pedogênese). In: KER, J.C.; CURI, N.; SCHAEFER, C.E.G.R. \& VIDAL-TORRADO, P., eds. Pedologia; Fundamentos. Viçosa, MG, Sociedade Brasileira de Ciência do Solo, 2012. p.208-248.

KARMANN, I. Evolução dinâmica atual do Sistema Cárstico do Alto Vale do Ribeira de Iguape, Sudeste do Estado de São Paulo. São Paulo, Universidade de São Paulo, 1994. 228p (Tese de Doutorado)

MIRANDA, C.S.S. \& FERREIRA, M.G.V.X. Caracterização de solos com A chernozêmico na zona da mata norte do estado de Pernambuco. R. Bras. Ci. Solo, 23:107-120, 1999.

MUNEER, M. \& OADES, J.M. The role of Ca-organic interactions in soil aggregate stability. III. mechanisms and models. Austr. J. Soil Sci., 27:411-423, 1989.

OADES, J.M. The retention of organic matter in soils. Biogeochemistry, 5:35-70, 1988.

OWLIAIE H.R.; ABTAHI A. \& HECK R.H. Pedogenesis and clay mineralogical investigation of soils formed on gypsiferous and calcareous materials, on a transect, southwestern Iran. Geoderma, 134:62-81, 2006.

RAMOS, D.P. \& MANZATTO, C.V. Levantamento semidetalhado de solos, aptidão agrícola das terras para culturas de sequeiro e classes de terras para irrigação do projeto especial de colonização da Serra do Ramalho Bom Jesus da Lapa - BA. Bom Jesus da Lapa, 1991. 543p. (Relatório Técnico, 1)

SANTOS, A.C.; PEREIRA, M.G.; ANJOS, L.H.; BERNINI, T.A.; COOPER, M.; NUMMER, A. \& FRANCELINO, M.R. Gênese e classificação de solos numa topossequência no ambiente de mar de morros do médio vale do Paraíba do Sul, RJ. R. Bras. Ci. Solo, 34:1297-1314, 2010.

SANTOS, H. G.; JACOMINE, P. K. T.; ANJOS, L. H.C.; OLIVEIRA, V. A.; OLIVEIRA, J. B.; COELHO, M. R.; LUMBRERAS, J. F. \& CUNHA, T. J.F., eds. Sistema brasileiro de classificação de solos.2 ed. Rio de Janeiro: Embrapa Solos, 2006. 306p.

SANTOS, R.D.; LEMOS, R.C.; SANTOS, H.G.; KER, J.C. \& ANJOS, L.H.C. Manual de descrição e coleta de solo no campo. 5.ed. Viçosa, MG, Sociedade Brasileira de Ciência do Solo/Embrapa Solos, 2005.

SHINZATO, E. O carste da área de proteção ambiental de Lagoa Santa (MG) e sua influência na formação de solos. Campos dos Goytacazes, Universidade Estadual do Norte Fluminense, 1998. 99p. (Dissertação de Mestrado)

SOUZA, E.A.; RIBEIRO, M.R. \& FERREIRA, V.X. Caracterização e gênese de solos do Baixio de Irecê (BA). R. Bras. Ci. Solo, 17:89-97, 1993.

VOLKOFF, B. \& CERRI, C.C. Húmus em solos da floresta Amazônica na região do rio Madeira. R. Bras. Ci. Solo, 5:15-21, 1981. 